\title{
Pain and Disability in the Jaw and Neck Region following Whiplash Trauma
}

Journal of Dental Research

2016, Vol. 95(10) II55-1160

(C) International \& American Associations

for Dental Research 2016

Reprints and permissions:

sagepub.com/journalsPermissions.nav

DOI: $10.1177 / 0022034516653598$

jdr.sagepub.com

\author{
B. Häggman-Henrikson ',2, E. Lampa', S. Marklund', \\ and A. Wänman'
}

\begin{abstract}
The relationship between whiplash trauma and chronic orofacial pain is unclear, especially with regard to the time elapsed from trauma to development of orofacial pain. The aim was to analyze prevalence of jaw pain and disability, as well as the relationship between pain and disability in the jaw and neck regions in the early nonchronic stage after whiplash trauma. In this case-control study, 70 individuals ( 40 women, 30 men, mean age 35.5 y) who visited an emergency department with neck pain following a car accident were examined within $3 \mathrm{wk}$ of trauma (group I) and compared with 70 individuals (42 women, 28 men, mean age 33.8 y), who declined to attend a clinical examination but agreed to fill in questionnaires (group 2). The 2 case groups were compared with a matched control group of 70 individuals (42 women, 28 men, mean age 37.6 y) without a history of neck trauma. All participants completed questionnaires regarding jaw pain and dysfunction, rating pain intensity in jaw and neck regions on the Numerical Rating Scale, the Neck Disability Index, and Jaw Disability Checklist. Compared with controls, individuals with a recent whiplash trauma reported more jaw pain and dysfunction. Furthermore, there was a moderate positive correlation between jaw and neck pain ratings for group I $(r=0.6 \mathrm{I}, P<0.000 \mathrm{I})$ and group $2(r=0.59, P<0.0001)$. In the logistic regression analysis, cases showed higher odds ratios (range, 6.I to 40.8$)$ for jaw and neck pain and disability compared with controls. Taken together, the results show that individuals with a recent whiplash trauma report more jaw pain and disability compared with controls without a history of neck trauma. Furthermore, the correlation between jaw and neck pain intensity implies that intensity of neck pain in the acute stage after whiplash trauma might be a possible risk factor also for development of chronic orofacial pain.
\end{abstract}

Keywords: myofascial pain, neurophysiology, neuroscience/neurobiology, orofacial pain/TMD, risk factor(s), temporomandibular disorders/TMD

\section{Introduction}

The term whiplash describes a hyperextension-flexion trauma to the neck. The incidence is about 2 per 1,000 inhabitants, mostly caused by trauma from traffic injuries (Styrke et al. 2012). Although most individuals will recover from an acute whiplash injury, up to one-third will develop long-lasting symptoms (i.e., whiplash-associated disorders [WADs]) (Sterner and Gerdle 2004; Kamper et al. 2008). Affected individuals commonly report headaches, neck pain, and disability (Sterner and Gerdle 2004) and widespread pain that may also involve the orofacial region (Häggman-Henrikson, List, et al. 2013).

Pain in the orofacial region is reported by approximately $10 \%$ of the general adult population, with a higher prevalence among women than men (LeResche 1997; Macfarlane et al. 2002; Lövgren et al. 2015). The most common cause for chronic orofacial pain is temporomandibular disorders (TMDs) (Maixner et al. 2011), which is embracing pain and disability in the temporomandibular joint (TMJ) and/or jaw muscles (Dworkin and LeResche 1992). TMDs have a negative effect on an individual's oral health and general well-being (Dahlström and Carlsson 2010). The etiology of TMD is considered multifactorial (Slade et al. 2013) and whiplash trauma has been proposed as one factor that can contribute to the onset (De Boever and Keersmaekers 1996; Häggman-Henrikson et al. 2014). The relationship between whiplash trauma and TMD is unclear, especially with regard to the time elapsed from the neck trauma to the development of TMD pain.

Comorbidity between pain in the jaw and neck regions has been reported for patients with neck pain and for patients with TMD (Visscher et al. 2001; Wiesinger et al. 2007). Furthermore, a reciprocal relationship between pain in the trigeminal and spinal regions has been demonstrated (Marklund et al. 2010). The jaw and neck regions have a close sensorimotor integration not only with regard to pain but also with regard to motor function (Eriksson et al. 2000; Häggman-Henrikson et al. 2006). Even though the pathophysiological mechanisms behind orofacial pain after whiplash trauma are unclear, it has

\footnotetext{
'Clinical Oral Physiology, Umeå University, Umeå, Sweden

${ }^{2}$ Department of Orofacial Pain and Jaw Function, Malmö University, Malmö, Sweden

Corresponding Author:

B. Häggman-Henrikson, Department of Orofacial Pain and Jaw Function, Malmö University, SE-205 06 Malmö, Sweden.

Email: birgitta.haggman.henrikson@mah.se
} 
been suggested to be a part of a chronic pain condition - that is, developing over time rather than being part of an acute syndrome (Severinsson et al. 2010; Häggman-Henrikson, List, et al. 2013). However, to understand the pathophysiology, it is important to investigate whether a relationship exists also in the acute phase after a whiplash trauma. The possible relationship between pain, function, and disability in the jaw and neck regions in the early stages after a whiplash trauma has, to our knowledge, not been reported.

The aim of the present study was to analyze the prevalence of jaw pain and disability, as well as the relationship between pain and disability in the jaw and neck regions, in the early nonchronic stage within 1 mo after a whiplash trauma. The null hypothesis was that no relationship exists between jaw and neck pain and disability in the early acute stage after a whiplash trauma.

\section{Materials and Methods}

\section{Study Sample}

From January 1, 2012, to January 9, 2015, all individuals who visited the emergency department at Umeå University Hospital, Sweden, with neck pain following a car accident were invited within $3 \mathrm{wk}$ after the accident for a clinical examination to the Department of Clinical Oral Physiology, Umeå. To evaluate the possible bias due to the likelihood that individuals with more pain may be more inclined to attend a clinical examination, we also included a group of individuals who declined to attend a clinical examination but agreed to fill in the questionnaire if posted to them. The 2 groups with neck trauma were compared with a control group with no history of trauma that was recruited through advertisement.

In total, 298 individuals were invited to participate. Overall, 70 consecutive individuals (40 women, 30 men, 18 to $69 \mathrm{y}$, mean [SD] age 35.5 [15.6] y) who accepted to attend a clinical examination and to fill in a questionnaire concerning pain and disability in the jaw and neck regions (group 1) were compared with 70 consecutive individuals (42 women, 28 men, 18 to $68 \mathrm{y}$, mean [SD] age 33.8 [13.4] y) who declined to attend a clinical examination but agreed to fill in the questionnaire if posted to them with a prepaid return envelope (group 2). The 2 case groups, respectively, were compared with a matched control group of 70 individuals (42 women, 28 men, 18 to $66 \mathrm{y}$, mean [SD] age 37.6 [14.0] y) without a history of neck trauma (controls). The study was carried out in accordance with the Declaration of Helsinki and was approved by the Regional Ethical Review Board in Umeå. Written informed consent was obtained from all subjects. This study complied with STROBE guidelines for observational studies.

\section{Data Collection}

The following items and questionnaires were included:

- Three questions on jaw pain and dysfunction (3Q/ TMD) (Lövgren et al. 2015)
- Question 1: Do you have pain in your temple, face, jaw, or jaw joint once a week or more?

- Question 2: Do you have pain once a week or more when you open your mouth or chew?

- Question 3: Does your jaw lock or become stuck once a week or more?

- Neck Disability Index (NDI) (Vernon 2008)

- Rating of current pain intensity in the jaw region on the Numerical Rating Scale (NRS)

- Rating of current pain intensity in the neck region on the NRS

- Jaw Disability Checklist (JDC) (Dworkin and LeResche 1992)

\section{Data Reduction and Statistical Analysis}

For the NDI, a 10-item scale with each item scored 0 to 5 , the scores were presented as percentages, where $0 \%$ to $8 \%$ represents no disability, $10 \%$ to $28 \%$ mild disability, $30 \%$ to $48 \%$ moderate disability, $50 \%$ to $68 \%$ severe disability, and $70 \%$ to $100 \%$ complete disability.

For the regression analysis, all items were dichotomized as follows:

- Answers to the 3Q/TMD questions: yes (1) or no (0)

- Pain intensity ratings (11-point NRS): 0 to 2 or $\geq 3$

- JDC (0 to 12$): 0$ or $>0$

- NDI $(0 \%$ to $100 \%): 0 \%$ to $8 \%$ or $>8 \%$

Comparisons between group 1, group 2, and controls were carried out with the Kruskal-Wallis test for NDI, JDC, and NRS ratings of jaw and neck pain and with Fisher's exact test for the 3Q/TMD. Analyses between individual groups were carried out with the Mann-Whitney $U$ test for the NDI, JDC, and NRS and with Fisher's exact test for the 3Q/TMD. Pearson's correlation was used to analyze the association between NRS ratings of jaw and neck pain. Odds ratios (ORs) and 95\% confidence intervals (CIs) were calculated in univariate binary logistic regression analyses with case groups and controls defined as dependent variables and NDI, JDC, and NRS ratings of jaw and neck pain and 3Q/TMD used as covariates. Results were considered statistically significant if the CI did not include 1 . For all statistical tests, a $P$ value $<0.05$ was considered statistically significant.

\section{Results}

Frequent jaw pain (once a week or more) was reported by $40.0 \%$ in group $1,27.1 \%$ in group 2 , and $5.7 \%$ of controls. Frequent pain on jaw movements was reported by $30.0 \%$ in group $1,11.4 \%$ in group 2 , and $2.9 \%$ of controls. Frequent jaw locking was reported by $17.1 \%$ in group $1,17.1 \%$ in group 2 , and $8.6 \%$ of controls (Fig. $1 \mathrm{~A}-\mathrm{C}$ ).

The median neck disability score was higher for both group $1(18.9, P<0.0001)$ and group $2(14.6, P<0.0001)$ compared with controls (4.1) (Fig. 2). 


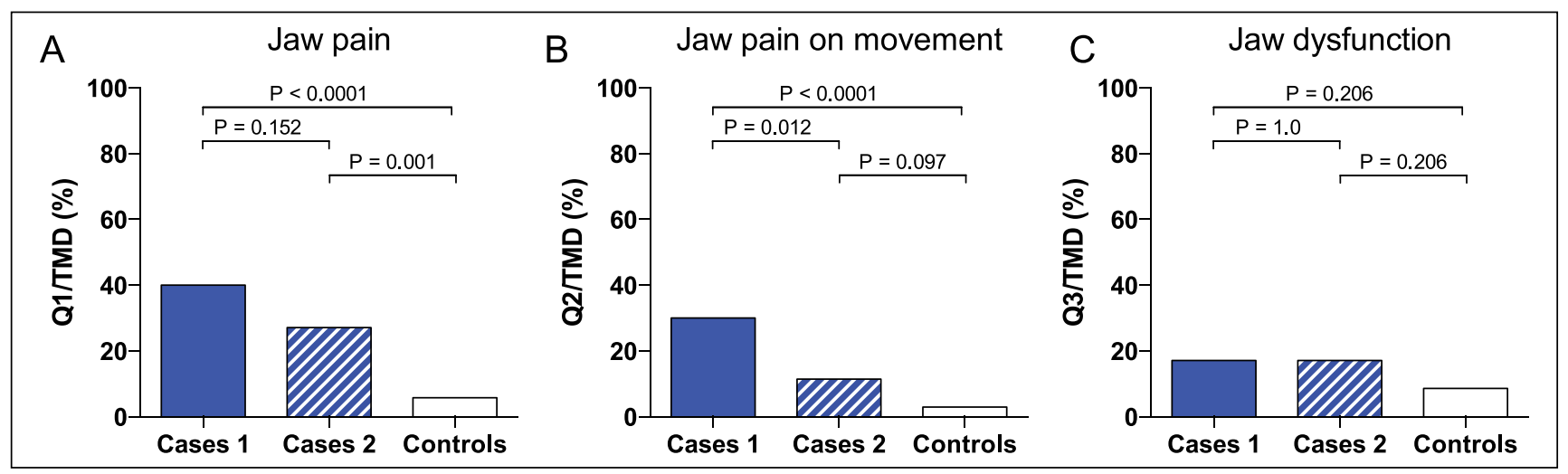

Figure I. Percentage of affirmative answers (\% yes) for the subjects in 3 groups: group I = individuals with recent neck trauma who completed a questionnaire and a clinical examination of the jaw system $(n=70)$, group $2=$ individuals with a recent neck trauma who completed a questionnaire but did not attend a clinical examination $(n=70)$, and controls $(n=70)$ who gave an affirmative reply to the following screening questions: A) Question $\mathrm{I}(\mathrm{Q} I)=$ Do you have pain in your temple, face, jaw, or jaw joint once a week or more? B) Question $2(\mathrm{Q} 2)=$ Do you have pain when you open your mouth or chew once a week or more? C) Question 3 (Q3) = Does your jaw lock or become stuck once a week or more? TMD, temporomandibular disorder.

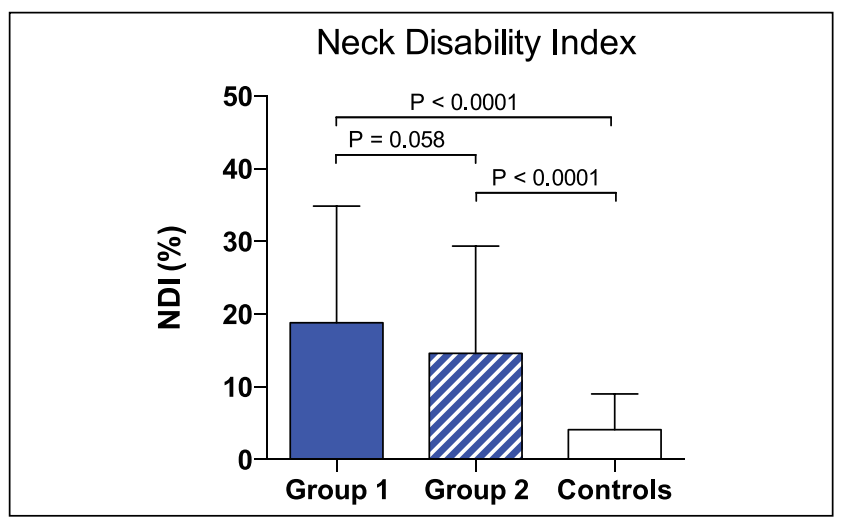

Figure 2. Neck Disability Index (NDI) score (\%) for the 3 groups: group I = individuals with neck trauma who completed a questionnaire and a clinical examination of the jaw system $(n=70)$, group $2=$ individuals with neck trauma who completed a questionnaire but did not attend a clinical examination $(n=70)$, and controls $(n=70)$.

Subjects with a recent neck trauma reported higher ratings of jaw pain intensity (group $1=1.3 \mathrm{NRS}, P<0.0001$; group $2=$ 0.7 NRS, $P=0.003)$ compared with controls $(0.1 \mathrm{NRS})$. Both case groups also reported higher neck pain intensity (group $1=$ 2.2 NRS, $P<0.0001$; group $2=2.1 \mathrm{NRS}, P<0.0001)$ compared with controls (0.3 NRS) (Fig. 3A, B).

Both group 1 and group 2 reported higher scores on the Jaw Disability Checklist $(0.6, P<0.0001$ and $0.7, P<0.0001$, respectively) compared with controls (0.1).

When the 2 case groups were compared with each other, frequent pain on jaw movements (question 2) was reported more often by group $1(P=0.012)$. Group 1 also reported higher intensity of jaw pain $(P=0.012)$, but there were no significant differences between group 1 and group 2 in prevalence of frequent jaw pain (question 1), frequent jaw locking (question 3), jaw disability (JDC), neck disability (NDI), or intensity of neck pain (NRS).

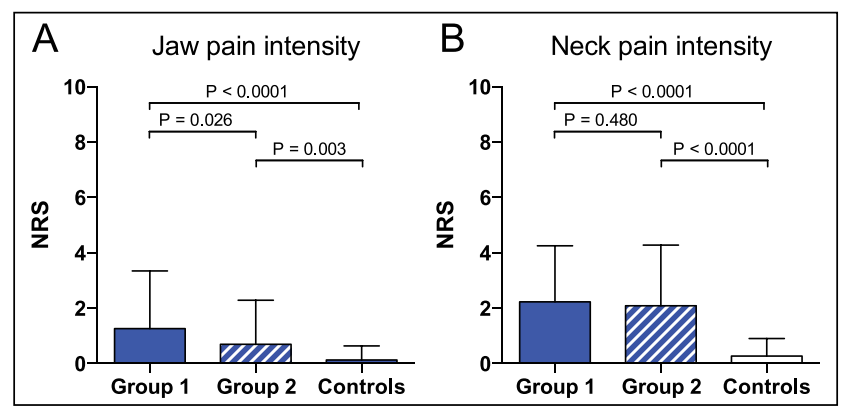

Figure 3. Jaw and neck pain ratings (Numerical Rating Scale [NRS]) for the 3 groups: group I = individuals with neck trauma who completed a questionnaire and a clinical examination of the jaw system $(n=70)$, group $2=$ individuals with neck trauma who completed a questionnaire but did not attend a clinical examination $(n=70)$, and controls $(n=70)$.

There was a moderate positive correlation between jaw and neck pain ratings for group $1(r=0.61, P<0.0001)$ (Fig. 4A) and group $2(r=0.59, P<0.0001)$ (Fig. 4B) but no correlation in the control group $(r=0.07, P=0.566)$.

The univariate regression analysis showed significantly higher odds ratios for group 1 and group 2 compared with controls for all tested variables except frequent locking of the jaw (for both groups 1 and 2) and pain on jaw movements for group 2 (Table).

\section{Discussion}

The main finding of the present study was that individuals with a recent whiplash trauma reported higher prevalence of jaw pain, higher pain intensity, and more neck disability compared with controls without a history of neck trauma. Furthermore, a correlation between reported pain intensity in the orofacial and neck regions was observed.

Most individuals are expected to recover after a whiplash trauma, but among those who develop chronic WAD, pain in 
Table. Logistic Regression Analysis of Groups I and 2 as Dependent Variables and Symptoms as Covariates.

\begin{tabular}{|c|c|c|c|c|c|c|c|c|}
\hline \multirow[b]{2}{*}{ Variables } & & \multirow{2}{*}{$\begin{array}{l}\text { Controls } \\
(n=70)\end{array}$} & \multirow{2}{*}{$\begin{array}{l}\text { Group I } \\
(n=70)\end{array}$} & \multirow{2}{*}{$\begin{array}{l}\text { Group } 2 \\
(n=70)\end{array}$} & \multicolumn{2}{|c|}{ Group I vs. Controls } & \multicolumn{2}{|c|}{ Group 2 vs. Controls } \\
\hline & & & & & OR $(95 \% \mathrm{Cl})$ & $P$ Value $^{\mathrm{a}}$ & OR $(95 \% \mathrm{Cl})$ & $P$ Value ${ }^{\mathrm{a}}$ \\
\hline QI & Yes & 4 & 28 & 19 & I I.0 (3.6 to 33.6) & $<0.0001$ & 6.1 (2.0 to I9.2) & 0.002 \\
\hline Q2 & Yes & 2 & 21 & 8 & I 4.6 (3.3 to 65.1$)$ & $<0.0001$ & $4.4(0.9$ to 21.5$)$ & 0.068 \\
\hline Q3 & Yes & 6 & 12 & 12 & $2.2(0.8$ to 6.3$)$ & 0.137 & $2.2(0.8$ to 6.3$)$ & 0.137 \\
\hline NDI & $\geq 10$ & II & 44 & 40 & 9.1 (4.I to 20.3$)$ & $<0.0001$ & 7.2 (3.2 to I5.9) & $<0.0001$ \\
\hline Neck pain ${ }^{b}$ & 3 to 10 & I & 25 & 26 & 38.3 (5.0 to 293.0$)$ & $<0.0001$ & $40.8(5.3$ to $3 \mid I .3)$ & $<0.0001$ \\
\hline Jaw pain & 3 to 10 & I & 14 & 8 & 17.3 (2.2 to 135.2) & 0.007 & $8.9(1.1$ to 73.2$)$ & 0.042 \\
\hline JDC & $\geq 1$ & 5 & 21 & 20 & $5.6(2.0$ to 15.8$)$ & 0.001 & 5.2 (I.8 to 14.8$)$ & 0.002 \\
\hline
\end{tabular}

Group I = individuals with neck trauma who completed a questionnaire and a clinical examination. Group $2=$ individuals with neck trauma who completed a questionnaire but did not attend a clinical examination. Question I $(\mathrm{Q} I)=$ Do you have pain in your temple, face, jaw, or jaw joint once a week or more? Question $2(\mathrm{Q} 2)$ = Do you have pain when you open your mouth wide or chew once a week or more? Question 3 (Q3) = Does your jaw lock or become stuck once a week or more?

$\mathrm{CI}$, confidence interval; JDC, Jaw Disability Checklist; NDI, Neck Disability Index; OR, odds ratio.

${ }^{a} P$ value $\leq 0.05$ is considered significant. Significant variables in bold text.

${ }^{b}$ Pain rated on the Numerical Rating Scale (0 to 10).

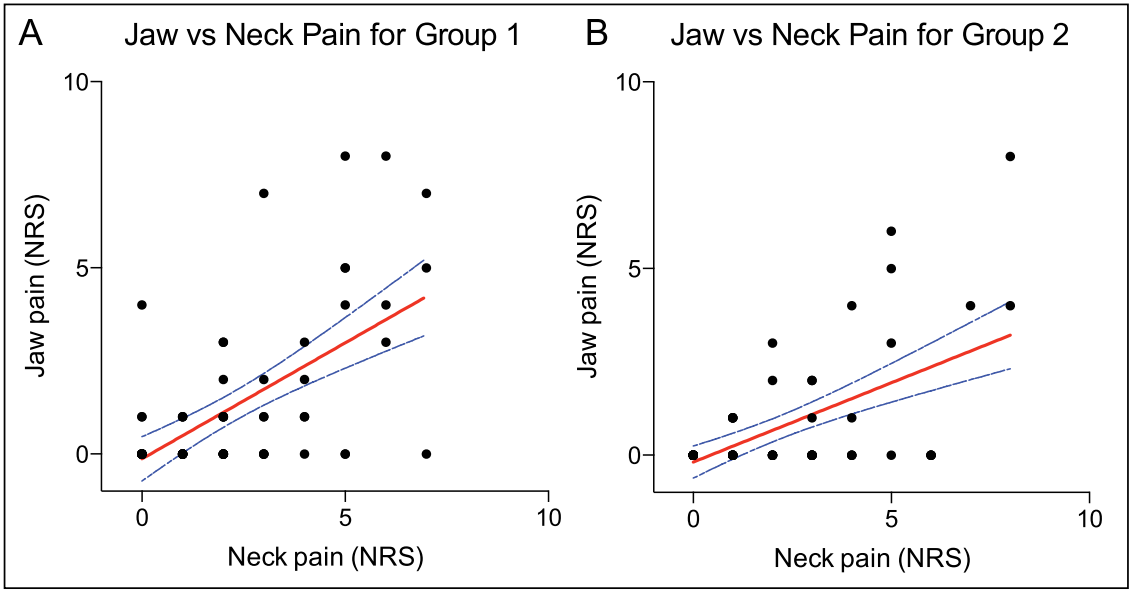

Figure 4. Scatterplot between jaw and neck pain ratings (Numerical Rating Scale [NRS]). (A) Group I = individuals with neck trauma who completed a questionnaire and a clinical examination of the jaw system $(n=70)$. (B) Group $2=$ individuals with neck trauma who completed a questionnaire but did not attend a clinical examination $(n=70)$.

the trigeminally innervated areas is commonly reported; in some studies of chronic WAD populations, more than $50 \%$ experience TMD pain (Visscher et al. 2005; HäggmanHenrikson et al. 2011; Häggman-Henrikson, List, et al. 2013). Different risk factors associated with development of chronic neck pain after a whiplash trauma have been suggested, but the intensity of neck pain in the acute stage has been identified as one of the strongest prognostic factors (Walton et al. 2013). In this perspective, the finding in our study that the intensity of neck pain was correlated to the intensity of jaw pain is interesting and may imply that intensity of neck pain in the acute stage after a whiplash trauma could be a possible risk factor also for the development of chronic orofacial pain.

The correlation between jaw and neck pain in our study can imply that the reported jaw pain was partly referred pain from the neck region rather than originating locally from the TMJ or jaw muscles. The pathophysiological mechanisms of TMD pain after whiplash trauma are unknown, but different explanatory models have been suggested. One early theory was that acceleration-deceleration of the headneck induced overstretching or compression of the TMJ, thereby causing a local injury. The concept was later refuted in favor of a neurobiological basis (Howard et al. 1998). This is also indirectly supported by a prospective study showing that even though no structural damage to the TMJ was found after whiplash trauma, about one-third of individuals still developed TMJ pain and dysfunction (Sale and Isberg 2007). There is further support both in experimental (Hellström et al. 2000; Svensson et al. 2004; SchmidtHansen et al. 2006) and clinical (Wiesinger et al. 2009) studies of overlapping spread and referral of muscle pain between the cervical and trigeminal regions. Thus, patients with TMD report more neck pain compared with the general population, and vice versa, patients with neck pain report more TMDs (De Laat et al. 1998; Visscher et al. 2001). In addition to an overlap, pain in one of these regions will increase the risk of developing pain in the other region (Marklund et al. 2010).

For the control group in our study, the outcome of the 3 screening questions (3Q/TMD) was similar to that recently reported for a population of approximately 140,000 individuals in northern Sweden (Lövgren et al. 2015). The case groups, on the other hand, reported significantly more positive replies, especially in relation to the 2 questions regarding frequent jaw pain and pain on jaw movement. This is also reflected by the high odds ratios in the regression analysis for affirmative answers to these 2 questions. This finding, together with the nonsignificant odds ratio for the question regarding frequent catching/locking of the TMJ, reinforces the notion of jaw pain after whiplash being related to muscle pain or referred pain rather than internal derangements of the TMJ. 
Patient-based outcomes have gained increased importance during the past decade (Dworkin et al. 2008), and the present study was based on self-reported pain and disability in the jaw and neck regions using the NDI, together with ratings of neck pain and jaw pain, as well as the 3 screening questions $(3 \mathrm{Q} /$ TMD) as surrogate measures for a clinically meaningful health state. The reported neck disability for both the control group and case groups was in line with previous reports for the population in general and in acute WAD (Walton et al. 2013). The NDI is validated and is the most commonly used questionnaire for assessing neck disability, especially in studies related to whiplash trauma (Vernon 2008), and the cutoff used in the present study is in line with recommendations (Kato et al. 2012). Jaw disability was assessed by the JDC, which is part of the validated Research Diagnostic Criteria (RDC)/TMD questionnaire (Dworkin and LeResche 1992). In our regression analysis, the JDC displayed high odds ratios in relation to the case groups. An association between jaw and neck disability has been reported for patients with TMD (Olivo et al. 2010; Silveira et al. 2015), but to our knowledge, our study is the first report on such a relationship in a case-control study investigating individuals with a recent whiplash trauma.

Causality cannot be demonstrated in a cross-sectional study, but possible risk factors can be identified for a later evaluation in prospective studies. Due to the low incidence of whiplash trauma, it can be difficult to design prospective studies that can follow a sufficient number of individuals before they are exposed to a whiplash trauma. In the thorough Orofacial Pain Prospective Evaluation and Risk Assessment (OPPERA) project, external trauma was one factor reported for onset of TMD pain at baseline, but in the prospective part of the project, incidence could not be predicted by self-reported history of external trauma (Slade et al. 2013).

The current study examined individuals within $3 \mathrm{wk}$ after the whiplash trauma. To evaluate the possible selection bias due to the likelihood that individuals with more pain may be more inclined to attend a clinical examination, we also included a group of individuals who declined to attend a clinical examination but agreed to fill in the questionnaires. The group that attended the examination (group 1) had significantly higher positive response to one of the screening questions (3Q/TMD) regarding frequent pain on jaw movement, and they also reported higher jaw pain intensity. Apart from these 2 items, there were no other significant differences between the 2 case groups. Taken together, this indicates that higher intensity of jaw pain and frequency of once a week or more will probe more individuals to attend a clinical examination of the jaw system. However, compared with the control group, the case group who did not attend the clinical examination still showed significantly more frequent jaw pain, higher intensity of jaw pain, and significant odds ratios for frequent jaw pain, jaw disability (JDC), and jaw pain intensity (NRS), which suggest that the main findings are reliable. The ratio between women and men in our study ( $57 \%$ vs. $43 \%$ ) was slightly higher than that reported by the Hospitals Injury register (52\% vs. 48\%) (Styrke et al. 2012), but we tried to minimize gender bias by using a matched control group. The fact that more women than men responded to the invitation to participate is in line with gender differences with regard to biological and psychosocial factors (Fillingim et al. 2009), as well as female sex being a predictor for a poor outcome following whiplash trauma (Walton et al. 2013).

There is an intricate relationship between the trigeminal and cervical motor systems, and head-neck movements are an integrated part of normal jaw function (Eriksson et al. 2000). A task-dependent proportional relationship between jaw and neck muscles has been suggested (Häggman-Henrikson, Nordh, et al. 2013), and experimental restriction of head-neck mobility in healthy subjects can impair jaw function (HäggmanHenrikson et al. 2006). Pain can be another cause of a disturbed neuromuscular control in the jaw-neck region, and an altered strategy for jaw-neck motor control after experimental pain has been demonstrated (Wiesinger et al. 2013). It has also been shown that patients with chronic WAD have impaired jaw movements (Häggman-Henrikson et al. 2002), reduced endurance, and pain during chewing (Häggman-Henrikson et al. 2004). In the present study, we found that individuals with a recent whiplash trauma reported more pain and disability in both the neck and jaw regions compared with controls without a history of neck trauma.

Orofacial pain in patients with chronic WAD has been suggested to be part of a widespread pain syndrome (Visscher et al. 2005). Compared with TMD patients without a history of neck injury, TMD patients with orofacial pain after whiplash trauma report more jaw dysfunction, headache, stress, dizziness, and sleep problems, indicating that TMD following whiplash trauma has a different pathophysiology (Häggman-Henrikson et al. 2014). Furthermore, patients with TMD related to whiplash trauma respond poorer to commonly used treatment options for TMD such as occlusal splints (De Boever and Keersmaekers 1996; Häggman-Henrikson et al. 2014). Taken together, this supports the notion of a different pathophysiology for these patients and may reflect spread of pain related to the close sensorimotor linkage between the jaw and neck regions, in addition to central sensitization with upregulated pain sensitivity and lowered sensory and pain thresholds. Thus, the process of central sensitization, associated increased pain sensitivity, and psychological and behavioral factors (Vlaeyen and Linton 2000) may play a role in the development of orofacial pain after whiplash trauma.

The main finding of the present study was that individuals with a recent whiplash trauma more often reported frequent jaw pain and disability compared with controls without a history of neck trauma. Furthermore, there was a positive correlation between the intensity of jaw pain and neck pain. Since intensity of neck pain in the acute stage has been identified as one of the strongest prognostic factors for poor outcome after a whiplash trauma (Walton et al. 2013), this finding may imply that intensity of neck pain in the acute stage after a whiplash trauma could be a possible risk factor also for the development of chronic orofacial pain. This hypothesis would need to be tested in a prospective study. 


\section{Author Contributions}

B. Häggman-Henrikson, contributed to conception, design, data acquisition, analysis, and interpretation, drafted and critically revised the manuscript; E. Lampa, contributed to conception, design, data acquisition, analysis, and interpretation, critically revised the manuscript; S. Marklund, contributed to design, data analysis, and interpretation, critically revised the manuscript; A. Wänman, contributed to conception, design, data analysis, and interpretation, critically revised the manuscript. All authors gave final approval and agree to be accountable for all aspects of the work.

\section{Acknowledgments}

The study was supported by grants from Västerbotten County Council (TUA), Folksam Research Foundation, Sigurd and Elsa Golje Memorial Foundation, the Swedish Association for Survivors of Accident and Injury (RTP), and the Swedish Dental Society. The authors declare no potential conflicts of interest with respect to the authorship and/or publication of this article.

\section{References}

Dahlström L, Carlsson GE. 2010. Temporomandibular disorders and oral health-related quality of life. A systematic review. Acta Odontol Scand. 68(2):80-85.

De Boever JA, Keersmaekers K. 1996. Trauma in patients with temporomandibular disorders: Frequency and treatment outcome. J Oral Rehabil. 23(2): $91-96$

De Laat A, Meuleman H, Stevens A, Verbeke G. 1998. Correlation between cervical spine and temporomandibular disorders. Clin Oral Invest. 2(2):54-57.

Dworkin RH, Turk DC, Wyrwich KW, Beaton D, Cleeland CS, Farrar JT, Haythornthwaite JA, Jensen MP, Kerns RD, Ader DN, et al. 2008 . Interpreting the clinical importance of treatment outcomes in chronic pain clinical trials: impact recommendations. J Pain. 9(2):105-121.

Dworkin SF, LeResche L. 1992. Research diagnostic criteria for temporomandibular disorders: review, criteria, examinations and specifications, critique. J Craniomand Disord. 6(4):301-355.

Eriksson PO, Häggman-Henrikson B, Nordh E, Zafar H. 2000. Co-ordinated mandibular and head-neck movements during rhythmic jaw activities in man. J Dent Res. 79(6):1378-1384.

Fillingim RB, King CD, Ribeiro-Dasilva MC, Rahim-Williams B, Riley JL III. 2009. Sex, gender, and pain: A review of recent clinical and experimenta findings. J Pain. 10(5):447-485.

Häggman-Henrikson B, Grönqvist J, Eriksson PO. 2011. Frequent jaw-face pain in chronic whiplash-associated disorders. Swed Dent J. 35(3):123-131.

Häggman-Henrikson B, List T, Westergren HT, Axelsson SH. 2013. Temporomandibular disorder pain after whiplash trauma: a systematic review. J Orofac Pain. 27(3):217-226.

Häggman-Henrikson B, Nordh E, Eriksson PO. 2013. Increased sternocleidomastoid, but not trapezius, muscle activity in response to increased chewing load. Eur J Oral Sci. 121(5):443-449.

Häggman-Henrikson B, Nordh E, Zafar H, Eriksson PO. 2006. Head immobilization can impair jaw function. J Dent Res. 85(11):1001-1005

Häggman-Henrikson B, Österlund C, Eriksson PO. 2004. Endurance during chewing in whiplash-associated disorders and TMD. J Dent Res. 83(12):946-950.

Häggman-Henrikson B, Rezvani M, List T. 2014. Prevalence of whiplash trauma in TMD patients: a systematic review. J Oral Rehabil. 41(1):59-68.

Häggman-Henrikson B, Zafar H, Eriksson PO. 2002. Disturbed jaw behavior in whiplash-associated disorders during rhythmic jaw movements. J Dent Res. 81(11):747-751.

Hellström F, Thunberg J, Bergenheim M, Sjölander P, Pedersen J, Johansson H. 2000. Elevated intramuscular concentration of bradykinin in jaw muscle increases the fusimotor drive to neck muscles in the cat. J Dent Res. 79(10): $1815-1822$

Howard RP, Bowles AP, Guzman HM, Krenrich SW. 1998. Head, neck, and mandible dynamics generated by 'whiplash'. Accid Anal Prev. 30(4): $525-534$
Kamper SJ, Rebbeck TJ, Maher CG, McAuley JH, Sterling M. 2008. Course and prognostic factors of whiplash: a systematic review and meta-analysis. Pain. 138(3):617-629.

Kato S, Takeshita K, Matsudaira K, Tonosu J, Hara N, Chikuda H. 2012. Normative score and cut-off value of the neck disability index. J Orthop Sci. 17(6):687-693.

LeResche L. 1997. Epidemiology of temporomandibular disorders: implications for the investigation of etiologic factors. Crit Rev Oral Biol Med. $8(3): 291-305$.

Lövgren A, Häggman-Henrikson B, Visscher CM, Lobbezoo F, Marklund S, Wänman A. 2015. Temporomandibular pain and jaw dysfunction at different ages covering the lifespan - a population based study. Eur J Pain. 20(4):532-540.

Macfarlane TV, Blinkhorn AS, Davies RM, Kincey J, Worthington HV. 2002. Oro-facial pain in the community: prevalence and associated impact. Community Dent Oral Epidemiol. 30(1):52-60.

Maixner W, Diatchenko L, Dubner R, Fillingim RB, Greenspan JD, Knott C, Ohrbach R, Weir B, Slade GD. 2011. Orofacial pain prospective evaluation and risk assessment study-the OPPERA study. J Pain. 12(11 Suppl):T4-11.e1-2.

Marklund S, Wiesinger B, Wänman A. 2010. Reciprocal influence on the incidence of symptoms in trigeminally and spinally innervated areas. Eur J Pain. 14(4):366-371.

Olivo SA, Fuentes J, Major PW, Warren S, Thie NM, Magee DJ. 2010. The association between neck disability and jaw disability. J Oral Rehabil. 37(9):670-679.

Sale H, Isberg A. 2007. Delayed temporomandibular joint pain and dysfunction induced by whiplash trauma: a controlled prospective study. J Am Dent Assoc. 138(8):1084-1091

Schmidt-Hansen PT, Svensson P, Jensen TS, Graven-Nielsen T, Bach FW. 2006. Patterns of experimentally induced pain in pericranial muscles. Cephalalgia. 26(5):568-577.

Severinsson Y, Bunketorp O, Wenneberg B. 2010. Jaw symptoms and signs and the connection to cranial cervical symptoms and post-traumatic stress during the first year after a whiplash trauma. Disabil Rehabil. 32(24):1987-1998.

Silveira A, Gadotti IC, Armijo-Olivo S, Biasotto-Gonzalez DA, Magee D. 2015. Jaw dysfunction is associated with neck disability and muscle tenderness in subjects with and without chronic temporomandibular disorders. BioMed Res Int. 2015:512792.

Slade GD, Fillingim RB, Sanders AE, Bair E, Greenspan JD, Ohrbach R, Dubner R, Diatchenko L, Smith SB, Knott C, et al. 2013. Summary of findings from the OPPERA prospective cohort study of incidence of first-onset temporomandibular disorder: implications and future directions. J Pain. 14(12 Suppl):T116-T124.

Sterner Y, Gerdle B. 2004. Acute and chronic whiplash disorders-a review. J Rehabil Med. 36(5):193-209.

Styrke J, Stålnacke BM, Bylund PO, Sojka P, Björnstig U. 2012. A 10-year incidence of acute whiplash injuries after road traffic crashes in a defined population in northern Sweden. PM\&R. 4(10):739-747.

Svensson P, Wang K, Sessle B, Arendt-Nielsen L. 2004. Associations between pain and neuromuscular activity in the human jaw and neck muscles. Pain. 109(3):225-232.

Vernon H. 2008. The neck disability index: state-of-the-art, 1991-2008. J Manipulative Physiol Ther. 31(7):491-502.

Visscher C, Hofman N, Mes C, Lousberg R, Naeije M. 2005. Is temporomandibular pain in chronic whiplash-associated disorders part of a more widespread pain syndrome? Clin J Pain. 21(4):353-357.

Visscher C, Lobbezoo F, de Boer W, van der Zaag J, Naeije M. 2001. Prevalence of cervical spinal pain in craniomandibular pain patients. Eur J Oral Sci. 109(2):76-80.

Vlaeyen JW, Linton SJ. 2000. Fear-avoidance and its consequences in chronic musculoskeletal pain: a state of the art. Pain. 85(3):317-332.

Walton DM, Macdermid JC, Giorgianni AA, Mascarenhas JC, West SC, Zammit CA. 2013. Risk factors for persistent problems following acute whiplash injury: update of a systematic review and meta-analysis. J Orthop Sports Phys Ther. 43(2):31-43.

Wiesinger B, Häggman-Henrikson B, Hellström F, Wänman A. 2013. Experimental masseter muscle pain alters jaw-neck motor strategy. Eur J Pain. 17(7):995-1004.

Wiesinger B, Malker H, Englund E, Wänman A. 2007. Back pain in relation to musculoskeletal disorders in the jaw-face: a matched case-control study. Pain. 131(3):311-319.

Wiesinger B, Malker H, Englund E, Wänman A. 2009. Does a dose-response relation exist between spinal pain and temporomandibular disorders? BMC Musculoskelet Disord. 10:28. 